\title{
D’une gaîté ingénieuse. «L'Histoire de Gil Blas», roman de Lesage, Études réunies par Béatrice Didier et Jean-Paul Sermain
}

\section{Regina Bochenek -Franczakowa}

\section{(2) OpenEdition Journals}

Édition électronique

URL : http://journals.openedition.org/studifrancesi/30296

DOI : $10.4000 /$ studifrancesi.30296

ISSN : 2421-5856

Éditeur

Rosenberg \& Sellier

\section{Édition imprimée}

Date de publication : 1 avril 2006

Pagination : 156-157

ISSN : 0039-2944

\section{Référence électronique}

Regina Bochenek -Franczakowa, "D'une gaîté ingénieuse. «L'Histoire de Gil Blas», roman de Lesage, Études réunies par Béatrice Didier et Jean-Paul Sermain », Studi Francesi [En ligne], 148 (XLX | I) | 2006, mis en ligne le 30 novembre 2015, consulté le 19 avril 2021. URL : http://journals.openedition.org/ studifrancesi/30296; DOI : https://doi.org/10.4000/studifrancesi.30296

Ce document a été généré automatiquement le 19 avril 2021.

\section{cc) (†)}

Studi Francesi è distribuita con Licenza Creative Commons Attribuzione - Non commerciale - Non opere derivate 4.0 Internazionale. 


\title{
D'une gaîté ingénieuse. «L'Histoire de Gil Blas», roman de Lesage, Études réunies par Béatrice Didier et Jean- Paul Sermain
}

\author{
Regina Bochenek -Franczakowa
}

\section{RÉFÉRENCE}

D’une gaîté ingénieuse. «L'Histoire de Gil Blas», roman de Lesage, Études réunies par BÉATRICE DIDIER et JEAN-PAUL SERMAIN, Londres, Louvain, Paris, Dudley, MA, Editions Peeters: («La Republique des Lettres», 18), 2004, pp. 326.

1 Ce recueil d'études sur Gil Blas de Lesage, fruit des rencontres à Paris III et à l'Ecole Normale Supérieure propose des lectures qui ne font pas oublier les traits dominants de ce roman, à savoir le comique et l'art de la composition. Les chercheurs ont décidé de ne considérer que les six premiers livres de Gil de 1715, indépendamment des livres ultérieurs publiés en 1724 et 1735: choix décisif car il permet d'examiner, à partir du texte lesagien, les propriétés de la poétique du roman d'Ancien Régime. Les études sont axées autour de cinq groupes thématiques. Le premier («L'histoire, le roman») explore certains traits de l'univers représenté du roman: GENEVIÈVE ARTIGAS-MENANT (LesageAsmodée dans «Gil Blas», pp. 21-37) compare Le Diable boiteux et Gil Blas afin de démontrer trois aspects de cette filiation - le prétexte pédagogique, le rôle de l'auteur et le principe esthétique. CECILE CAVILLAC (Picaresque et merveilleux dans les six premiers livres de «Gil Blas», pp. 38-50), après avoir situé le texte lesagien dans la tradition du roman picaresque européen, considère les caractères de divers écarts de celui-là par rapport au modèle d'origine, soulignant la part du merveilleux. GÉRARD LAHOUATI (Les vivants et les morts. L'«Histoire de Gil Blas de Santillane» comme roman initiatique, pp. 51-65) étudie l'épisode des brigands (livre I, chapitres 3-10) par le biais de ses fonctions narrative et 
symbolique. Il en ressort que Gil Blas sort changé de cette épreuve qui a tous les traits d'une initiation.

2 La deuxième partie («Personnages») contient des études consacrées à la problématique du personnage. Françoise Gevrey (Gil Blas, le personnage introuvable, pp. 69-90) examine le personnage éponyme lequel, devenu quasi transparent, se dilue au long du roman: le lecteur découvre ainsi dans le roman «une intention de déconstruire lepersonnage et, à travers lui, l'illusion romanesque de l'époque classique». CATHERINE VOLPILHAC-AUGER (Diego le simple, Diego le double, pp. 91-103) veut prouver que1'histoire de Diego de la Fuente est une sorte de double de celle de Gil Blas: on est en présence d'un texte qui semble se constituer à travers une «mise en abyme» du roman entier. CHRISTELLE BAHIERPORTE (Entre caractère et mystère: les portraits dans «Gil Blas»: pp. 104-120) considère les «portraits» des personnages lesagiens, placés tous sous le signe de la parodie et la satire. La troisième partie («Le sublime du comique») est consacrée au comique dans ce roman de Lesage. JACQUES WAGNER (Le rire de Lesage dans «Gil Blas de Santillane» /1715/, pp. 123-139) distingue trois types de rire qu'il étudie en rapport avec les trois strates du roman qui y correspondent: le rire originel, le rire verbal ou textuel, le rire critique ou culturel. En somme, le rire de Lesage est «un rire intérieur qui vise le donquichottisme de la culture noble». Aux yeux de JEAN-FRANçOIS PERRIN (Sur la référence théâtrale dans les six premiers livres de "Gil Blas», pp. 140-154) le roman de Lesage presente le cas d' "une marqueterie narrative incrustée de théâtralité», en même temps qu'une histoire comique et un roman de comédiens. ERIK LEBORGNE examine le comique du roman de Lesage à travers l'alliance du grotesque et de l'humur noir, et en montre ensuite l'application chez Prévost et Diderot (Grotesque et humour noir dans "Gil Blas», pp. 155-175).

Dans la quatrième partie («Figures en mosaïque») se trouvent des études variées. RENÉ DÉMORIs (L'économie des échanges dans le "Gil Blas» de 1715, pp. 179-199) analyse l'économie des échanges dans le roman pour prouver que le pessimisme des romans «picaresques», où les relations humaines sont basées sur la rapacité, se transforme chez Lesage en un "optimisme désespéré» qui est déjà du $18^{\mathrm{e}}$ siècle. JACQUES BERCHTOLD ( $L a$ leçon de Sangrado. Le double registre du sanglant dans «Gil Blas» pp. 200-250) propose la thèse selon laquelle le roman de Lesage présente une hésitation du genre des pseudomémoires entre le roman picaresque et la tragédie racinienne. SYLVAIN MENANT («Gil Blas» entre séries externes et séries internes, pp. 251-260) attire l'attention sur la structure sérielle du roman, les «séries» pouvant être internes ou externes. L'ensemble du roman permet de dégager un sens lié à une vision du monde comme théâtre. La cinquième partie («Ingéniosité postcritique») est centrée sur les problèmes de l'art romanesque. MARC ESCOLA (Récits perdus à Santillane, pp. 263-279) se penche sur les «récits perdus», c'est-à-dire annoncés sans être racontés. Le nombre de ces récits prouve que ce qui commande la composition du roman lesagien est non pas la diversité, mais «une gestion concertée des possibles narratifs». CHRISTOPHE MARTIN («Gil Blas» ou le jeu des apparences, pp. 280-297) démontre que la seule vérité dans Gil Blas se trouve du côté de la fable: la vérité, dit Lesage, «n'a pas à être atteinte, trouvée ni reproduite: elle doit être créée». Le recueil est clos par l'étude du langage dans Gil Blas. JEAN-PAUL SERMAIN y dégage trois modes d'activités linguistiques les plus riches de sens: la parole séductrice, l'éloge paradoxal, enfin, le récit libertin (Lesage et le langage de Gil Blas, pp. 298-310). BÉATRICE DIDIER en guise de conclusion (Sans vouloir conclure, pp. 311-312), fait remarquer la pluralité des lectures possibles de Gil Blas et souligne l'«ouverture» de ce roman qui 
est à la source du plaisir stimulant de la lecture. À la fin du volume, l'on trouve une très riche Bibliographie des études consacrées à Lesage et à son roman (pp. 321-326). 